\title{
Development of calcium rich food products with finger millet malt (Eleusine coracana L.)
}

See end of the paper for authors' affiliations

\section{JAISHREE BHALERAO}

Department of Foods and Nutrition, College of Home Science, Vasantrao Naik Marathwada Krishi Vidyapeeth, PARBHANI (M.S.) INDIA

Email : jaishreebhalerao01@ rediffmail. com
-ABSTRACT : Finger millet (Eleusine coracana) is rich in protein, iron, calcium, phosphorus, fibre and vitamin content. The calcium content is higher than all cereals. Finger millet is a versatile grain that can be used in many food preparations. Malting of finger millet improves its digestibility, sensory and nutritional quality as well as pronounced effect in lowering the antinutrients. Hence, the study was undertaken to develop calcium rich products with finger millet malt.In first phase of study finger millet malt was prepared and three products viz., biscuits, Pohe Papad and vermcelli were selected for development. Finger millet malt was incorporatedat the levels of 0,10,20,30, 40 in biscuits and 0,10,15,20,25 per cent in Pohe Papad and vermcelli along with soybean 20 per cent. Five variations of each product were prepared. Variation I was basic prepared without finger millet malt served as control sample and remaining four variations were experimental samples. In second phase of study all the products were organoleptically evaluated by panel members for their acceptability. The most accepted variation was selected for nutrient analysis. The proximate composition, fibre, calcium and iron were estimated in the laboratory. The results revealed that malted finger millet incorporation upto 30, 15 and 20 per cent in biscuits, Pohe Papad and vermcelli, respectively was accepted by panel members. Significant increase in values of nutrient i.e. protein, fibre, total mineral,iron and calcium was noticed in experimental variations of biscuits. Incorporation of finger millet malt in Pohe Papad and vermcelli could help to increase protein, fibre and calcium significantly. It can be concluded from the findings of the study that finger millet malt can be utilized successfully for development of calcium rich food product.

KEY WORDS: Finger millet malt, Calcium, Fibre, Protein

- HOW TO CITE THIS PAPER : Bhalerao, Jaishree and Farzana, Farooqui (2016). Development of calcium rich food products with finger millet malt (Eleusine coracana L.). Asian J. Home Sci., 11 (2) : 291297, DOI: 10.15740/HAS/AJHS/11.2/291-297. 